\title{
Students' Perceptions Towards Using Web 2.0 Technologies in Education
}

\author{
http://dx.doi.org/10.3991/ijet.v10i6.4858 \\ Rdouan Faizi, Raddouane Chiheb and Abdellatif El Afia \\ ENSIAS, Mohammed V University, Rabat, Morocco
}

\begin{abstract}
The purpose of this paper is to evaluate the usefulness of Web 2.0 technologies in education. For this purpose, a survey was carried out to explore the students' perceptions towards using these tools for learning purposes. Results of the research study revealed that all the respondents are greatly immersed in these social platforms and use them for many reasons. However, it was found out that almost half of the surveyed students (i.e. $47 \%$ ) devote more than $40 \%$ of the time they spend on Web 2.0 technologies to enhance their learning in different subjects. Taking these findings into consideration, we can stipulate that Web 2.0 applications present many educational advantages for students, hence, contribute in providing opportunities for further learning. Consequently, these online tools provide schools and universities with more opportunities to go beyond traditional delivery formats and develop learnercentered personalized learning environments.
\end{abstract}

Index Terms-Web 2.0 technologies, higher education, survey, students' perceptions

\section{INTRODUCTION}

In the past, the internet served chiefly as a "read-only" information repository as content was provided only by people with specialized skills. Users could only view web pages but could not edit, correct or add any content. However, in the last few years, the web has turned into a "readwrite" venue for creation, discussion, collaboration and social interaction. Consequently, internet users are now content creators and the primary drivers of this emerging participatory culture rather than being simple consumers of knowledge and information. Today, users do not only have the possibility to read or collect information, but they can also contribute to, collaborate on and edit that information.

The result of this second generation of the web has been the emergence and proliferation of a set of online social platforms, collectively known as Web 2.0 technologies. These applications have various forms and functions, but all share the common characteristic of enabling and supporting web-based interactions within and between different groups. Web 2.0 technologies are widely used by millions of people across different fields and for a variety of purposes. As such, they have changed the way in which individuals, institutions and organizations interact with each other. Students, for instance, are immersed in these web-applications and resort to them in nearly all their daily activities. They use them to communicate with friends and strangers, do research, and most importantly to learn. These online social spaces are actually an essential resource for students across all disciplines and subjects.

Given the increasing use of Web 2.0 technologies for educational purposes, many educators are questioning the usefulness and validity of using these tools in education. Though a lot of research studies have demonstrated that these platforms have educational benefits, many faculty members still claim that these tools have a negative impact on the performance of students.

The objective of the present paper is, therefore, to examine the relationship obtaining between Web 2.0 technologies and students' learning. Specifically, we will investigate the potential impact that these social platforms may have on education based on students' perceptions towards using these online tools.

The remainder of the present work is structured as follows. In Section Two, we briefly describe the major types of Web 2.0 technologies. In Section Three, we outline the potential advantages and disadvantages of using these technological tools in education. Section Four presents the results of a study undertook to examine students' perceptions towards using these web-based applications for educational purposes. Finally, Section Five gives a brief conclusion.

\section{MAJOR TYPES OF WEB 2.0 TECHNOLOGIES}

Web 2.0 technologies are generally associated with a variety of meanings that include emphasis on user generated content, information sharing, collaborative efforts, new ways of interacting with Web-based applications as well as the use of the Web as a social platform for creating, repositioning and consuming content [1]. In this section, we present the most popular Web 2.0 technologies. These include social networks, blogs, micro-blogs, wikis, discussion boards, bookmarking, media sharing and RSS.

\section{A. Social Networks}

Social networks are defined as web-based services, platforms or websites that enable individuals to communicate, interact and share ideas, messages, comments, photos, videos or any other content with a network of friends on the site or with a much wider audience over the Internet. In this sense, these public or semi-public profile-based online networks encourage individuals with common or similar backgrounds, activities or interests to develop and initiate relationships with one another [2]. The purpose of social networking sites is to provide an online virtual community that not only promotes the individual, but also emphasizes the individual's relationships within this community [3].

These networking sites are essentially composed of a representation of each user (often a profile), his social links as well as a variety of additional services. These networks have become a phenomenon in today's popular culture and nearly everyone is part of at least one these of 
these communities. Some of the most popular social platforms are Facebook, LinkedIn, MySpace and Viadeo.

\section{B. Wikis}

Wikis are collaborative websites that anyone within a community of users can contribute to or edit. Wikis can be open to a global audience or can be restricted to a specific network or community. A Wiki can cover a specific topic or subject area. The largest and most popular wiki is Wikipedia, a user-contributed online encyclopedia currently hosting millions of articles in more than 200 languages. Once published, an article on a Wiki is considered to be living content as it is always subject to changes and amendments by any user.

\section{Discussion forums}

A discussion board, also called discussion forum or online forum, is a space in which participants can get engaged in an exchange of information about a particular topic. It provides a venue for questions and answers and is usually monitored by a moderator to keep the content appropriate. Conversation in these boards is organized into topic-based discussion threads. Thus, all messages on a given topic are grouped together, allowing users to follow connected threads of thought. Another major feature of discussion forums is that they are usually asynchronous. This means that participants do not need to be logged in at the same time but can read and post comments or answers to others' messages whenever convenient.

\section{Blogs}

A Blog is a weblog or journal that allows users to share a running $\log$ of events and personal insights on a particular issue, event or topic with online audiences. Blogs are usually written and maintained by a single person and are updated on a regular basis with entries displayed in reverse chronological order. By being controlled by an individual, the blog is user-centered. As such, it gives the person not only a sense of ownership but also a sense of individual empowerment, ant it serves as a vehicle for expressing self-directedness [4]. Visitors to the blog can comment on the entries made or respond to comments made by other visitors. Today, blogs have become a major mainstream form of asynchronous communication over the Internet, and they are either self-hosted or integrated in some popular online software platforms [5].

\section{E. Micro-blogs}

A Micro-blog, as its name suggests, provides a similar function as a traditional blog, but with a much stronger focus on brevity. A micro-blogging website enables users to write short text messages (usually 140 characters) and publish them in real-time so that they could be viewed either by anyone or by a restricted group chosen by the user. The most popular examples of micro-blogging services include Twitter and FriendFeed.

\section{F. Social Bookmarking}

Social Bookmarking websites, also termed collaborative tagging systems, are centralized online services which allow users to store and share Internet bookmarks. These systems allow the user to store, classify, share, and search his own Internet bookmarks as well as those of other community members by using tags (folksonomies). Usually organized by topic, bookmarks can be saved in private, shared with some people or groups, or available to the whole public. Delicious, Digg, Reddit, Stumbleupon, to name just a few, are some examples of websites offering bookmarking services.

\section{G. Media sharing}

Media sharing sites enable users to upload and share their multimedia content (photos, videos and audio) with others on the web. Other users can view and download these media files. They can also enrich them with tags and captions as well as send/receive feedback on these multimedia files. Popular media sharing applications include YouTube, Dailymotion, Vimeo, Flickr, iTunes, Shutterfly and SlideShare.

\section{H. RSS}

RSS (Really Simple Syndication), an XML-based format for sharing and distributing regularly changing Web content. RSS is a common component of many Web 2.0 platforms as well as of most news related sites. It allows these platforms to distribute their updated and dynamic content as feeds to users' devices as soon as it is published. Therefore, instead of consulting a website regularly, subscribed users to RSS feeds can have all the news and content they desire right at their fingertips.

These Web 2.0 platforms can be grouped into three main categories. The first category consists of social networking sites such as Facebook, LinkedIn, MySpace and Twitter that serve as online communities via which individuals connect and interact with other people. The second category includes content sharing and organizing online platforms like YouTube, Slideshare, Dropbox, Digg, Delicious, Reddit, and RSS readers. The third category is composed of content creation and editing sites such as Blogger, Google Docs, Wikipedia and WordPress. Nevertheless, the features and functions of Web 2.0 platforms often overlap, making a technological tool appropriate for more than one category.

\section{WEB 2.0 TECHNOLOGIES: EDUCATIONAL ADVANTAGES AND DRAWBACKS}

Most of the studies conducted on Web 2.0 technologies and their impact on education have reported that these tools have many advantages $[6,7]$. One major benefit of these platforms is that they can serve as collaborative and knowledge platforms via which community members can share their knowledge with the group, post information, work together, and critically discuss issues [8].

One popular range of these applications are collaborative writing tools, namely blogs and wikis. These applications enable students and/or teachers to collaborate consecutively or simultaneously on producing a document or a set of documents over the Web. Henceforth, instead of dividing up an assignment or providing separate parts of a given task, students can work together jointly, intellectually and socially to achieve common objectives. Given this, Web 2.0 platforms offer both faculty and students a single destination in which they can bring their ideas together.

An additional advantage of using Web 2.0 applications as educational tools is that they can lead to increased student engagement $[9,10,11]$. Engagement refers to the time, energy as well as resources that a student devotes to any activity designed to enhance learning [12]. As Web 2.0 applications have been attracting millions of users around the globe, these technological tools can also draw 
the attention of students to the learning resources and opportunities available on the web [13]. Consequently, a student who rarely participates in class, because he is bored, intimidated or shy can get actively engaged or reengaged in co-constructing his learning experience with his teachers and peers. He can even feel more comfortable to voice his opinion and share his ideas and resources on Facebook, Twitter, or YouTube [14].

In addition to fostering collaboration and engagement, Web 2.0 applications also promote communication not only between students and teachers, but also amongst students, within and between classes. Using an online discussion forum or a social network, students can ask questions, make comments as well as get instant feedback from both teachers and peers. For their parts, teachers can answer students' questions, post assignments, extend inclass discussions and announce upcoming activities or events. Since these social platforms can be accessed anywhere and at anytime, students and teachers can have more opportunities to interact with each other [15]. This increasing number in teacher-student and student-student interactions can help better understand and solve learning difficulties. As a result, students will be able to learn quickly and a high level.

Despite the positive impact that Web 2.0 may have on education, a number of critics argue that there are serious risks to using these tools. One of the major drawbacks of this set of websites is that they distract students from their school work. Though a student logs in just to answer a message or to check a notification, he could be easily lured in for hours browsing videos and photos, which may reduce the amount of time spent on educational activities. Thus, students can be distracted and, consequently, put off their work. Not only does this execute pressure on the student to finish his work in a shorter period of time, but it can be detrimental to his success. Web 2.0 applications are, therefore, dangerous for students because they are unfulfilling time-wasters that distract students from work or real social activities [16].

Some educational experts also stipulate that Web 2.0 technologies also have a negative impact on students' communication skills. In fact, though these websites are good for building connections, some educators believe that the more time students spend on these online communities, the less time they will spend on interacting face-toface with others. As such, they will not be able to communicate and socialize effectively in person with others. Students' writing skills are also said to be affected. Since some students mostly use slang words or shortened forms of words on social networking sites and always rely on computer grammar and spelling checking features, command over language use is reduced. Given all these facts, teachers are getting more and more unsatisfied with the students' oral and writing communication skills [17].

As seen above, Web 2.0 technologies are argued to enhance students' learning experience. However, some educators maintain that these social websites prevent successful learning and are emotionally destructive to users. For this reason, to check whether Web 2.0 technologies are really beneficial or harmful to students, we present in the section that follows the results of a research study we undertook to evaluate the students' perceptions towards using Web 2.0 technologies for educational purposes.

\section{Students' Use of Web 2.0 Technologies}

Having discussed with the advantages and drawbacks of using Web 2.0 technologies in education, our objective in this section is to explore how students perceive the use of these tools for educational purposes.

\section{A. Research Methodology}

To see how effective Web 2.0 technologies are in enhancing students learning, a research survey was carried out to elicit students' perceptions about using these online tools for educational purposes. In this respect, a webbased anonymous questionnaire was administered to a group of higher education students. By using an online rather than a paper questionnaire, the intention was to reach the majority of participants and achieve a very high response rate.

The questionnaire is composed of two parts. The first part collects information related to the students' use of Web 2.0 platforms. The second part gathers data about the subjects' perceptions towards using these technological tools for study purposes.

The survey's target population were students from ENSIAS, Mohammed V University, Morocco. A link to the questionnaire was sent via e-mail in June 2014 to about 450 students. 382 students answered the questionnaire. 167 are females and 215 are males and their age varies between 18 and 23 .

\section{B. Data Analysis}

Analysis of the collected data revealed that all the surveyed students have a profile in at least one social networking website. This finding is not actually surprising given that the institution they attend is specialized in Information and Communication Technologies. For more information about the online social communities in which students are members, consider Figure 1.

As is clearly seen in Figure 1, the most popular social networks are among Moroccan higher education students are Facebook $(100 \%)$, Google $+(72 \%)$, and Twitter $(55 \%)$. LinkedIn (49\%) and Viadeo (20\%), however, are used on a lesser scale. The low percentage associated with both communities may be due to the fact that these online platforms are mainly business-oriented. As such, they may not be of great benefit to students.

Students also use another variety of Web 2.0 technologies, namely media sharing websites, forums, blogs and wikis. For illustration, consider the Figure 2.

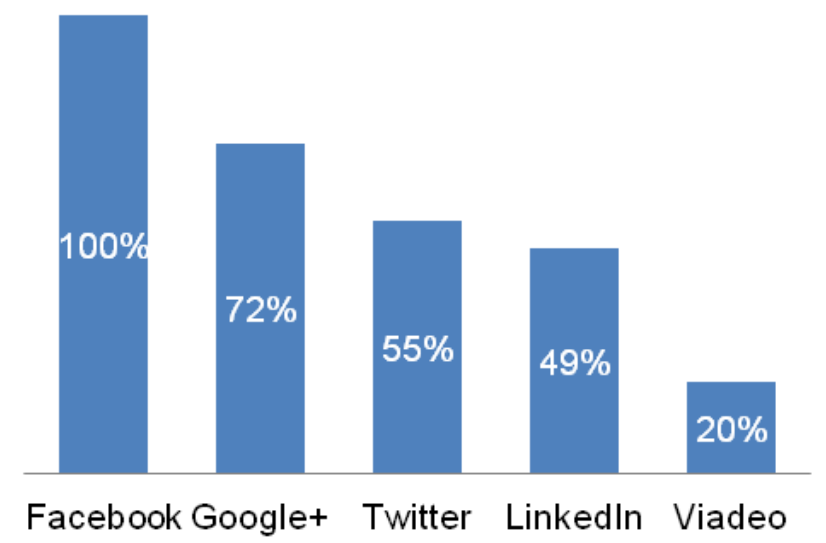

Figure 1. Students' membership in social networking sites 


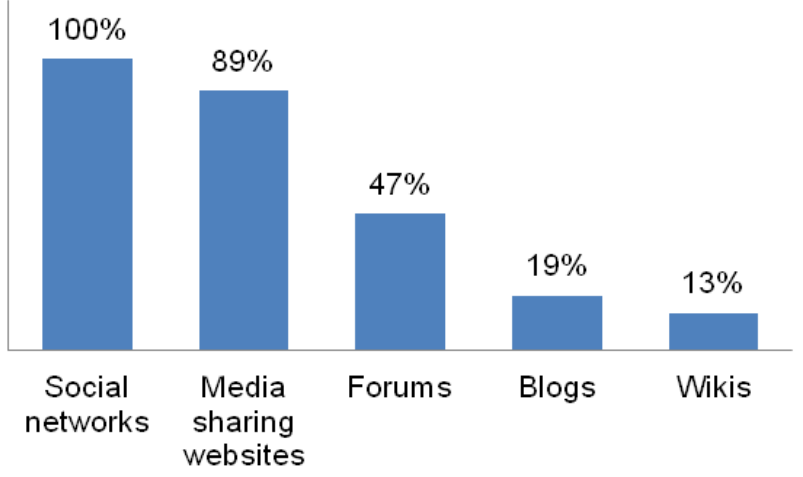

Figure 2. Web 2.0 technologies that students use

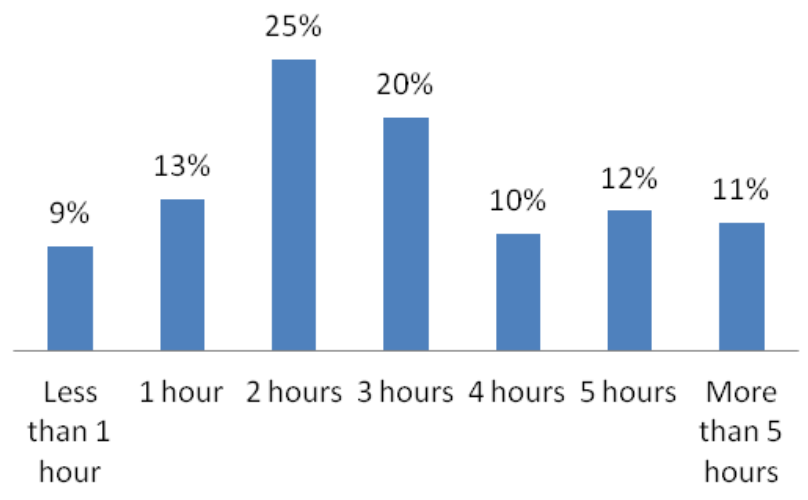

Figure 3. Daily mean time that students spend on Web 2.0 technologies

As is seen above, the second most widely used range of Web 2.0 technologies among students are media sharing applications (89\%). The most frequently used social media tool in this set is YouTube. The latter has actually been proven to increase participation, customization and productivity [18]. It was also claimed that YouTube improves students' digital skills and provides an opportunity for peer learning and problem solving [19]. The videos that this platform hosts keeps students' attention, generate interest in the subject and clarify course content. Other popular media sharing applications that students mentioned are Dailymotion and SlideShare.

In addition to social networks and media sharing websites, the study revealed that $47 \%$ of the students also use discussion forums to share ideas, get feedback, and benefit from the knowledge and experiences of classmates and those of other internet users. Blogs, which students can use to publish their own writings, discuss group assignments, peer review each other's work, collaborate on projects and manage their digital portfolios, are used only by $19 \%$ of the correspondents. Nevertheless, wikis, which can promote collaborative learning amongst students, are less popular as they are only used by $13 \%$ of the informants.

Concerning the mean amount of time per day that students spend on Web 2.0 technologies, it was found out that a significant proportion of the participants $(90 \%)$ devote more than one hour a day to these social online platforms. For illustration, consider Figure 3.

As the figure shows, the great majority of the subjects (78\%) spend more than 2 hours per day browsing these websites. Only $9 \%$ of the students get connected for less than 1 hour. This means that accessing a social online

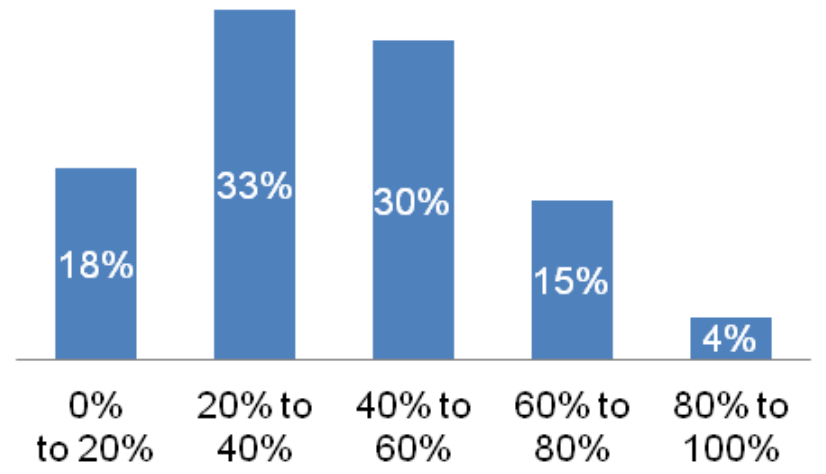

Figure 4. Daily mean time that students devote to study purposes on Web 2.0 technologies

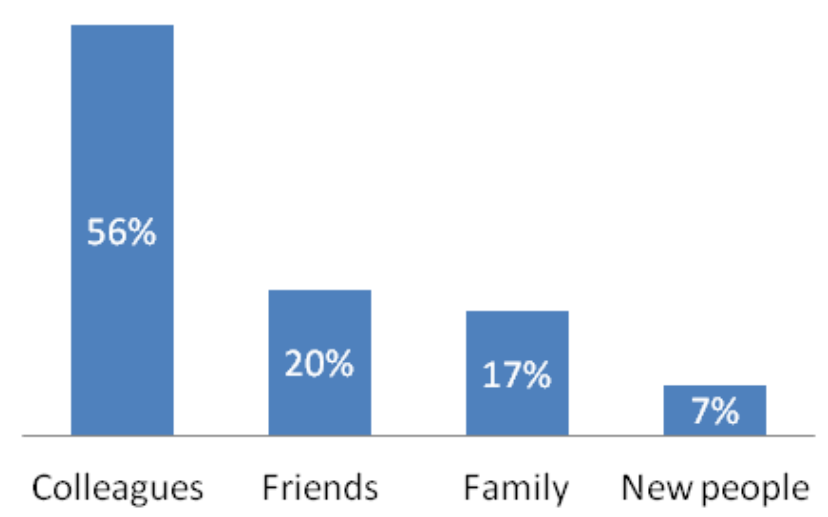

Figure 5. People who students interact with on Web 2.0 technologies

platform is a one of the primary daily tasks that a student has to accomplish. The excessive use of these online communities may, consequently, have a negative impact on students' performance.

However, what is worth noting here is that the interviewed students use these technologies not only to interact, play and explore, but also to learn. This means that in addition to using Web 2.0 technologies for personal reasons, $49 \%$ of the students claimed to devote more than $40 \%$ of the time they spend on these online applications to enhance their learning in different subjects. See Figure 4.

Web 2.0 technologies are, therefore, used for a variety of reasons. Nevertheless, improving one's learning experience is actually one of the main motives behind using these tools. This is, in fact, confirmed by the range of people that students interact with on these platforms. Consider Figure 5.

As Figure 5 shows, the people who students communicate most with on Web 2.0 technologies are colleagues and classmates $(56 \%)$. Given this, communication or discussion amongst students is likely to be around educational issues.

Concerning the students' contributions on Web 2.0 technologies, this study revealed that $97 \%$ of the students are actively involved in creating educational content on the Internet and, thus, participate in this learning give-andtake experience. In fact, students claimed to post learning materials and resources such as lessons, tutorials, tests, answers to exercises, as well as any other information that might be interesting to classmates or colleagues.

However when students were asked whether Web 2.0 technologies could replace traditional teaching/learning 
methods, $19 \%$ of the subjects claimed that these online tools can actually be an alternative to classroom based education. Following these informants, media sharing websites such as YouTube feature a broad set of educational videos in a variety of languages, and they noted that getting enrolled in these video courses and tutorials is often much more efficient than face-to-face teaching. 59\% of the surveyed students, however, were neutral but all agree that these applications play a major role in enhancing their learning experience. The rest (i.e. $22 \%$ ) argued that Web 2.0 technologies will never take the place of learning in class but should supplement it.

All these findings clearly indicate that Web 2.0 technologies have positively impacted education and changed the landscape of learning. Though a lot of criticism has been leveled at these online tools and the negative effect they may have on the way students process and retain information, the educational advantages of these social platforms outweigh their drawbacks.

\section{CONCLUSION}

This paper aimed at investigating the perceptions of students towards using Web 2.0 technologies in education. To that end, a research survey was carried among higher education students. Results of the research study revealed that all students are immersed in these web-based applications and have recourse to them for a variety purposes. However, it has been found out a significant proportion of the informants actually use these online applications as educational tools that help them to broaden and deepen their knowledge in specific areas of studies. Given this fact, we recommend that these online tools are capable of enriching the learning experience. Therefore, they should be made use of in different learning environments.

\section{REFERENCES}

[1] A. L Harris and A. Rea, "Web 2.0 and Virtual World Technologies: A Growing Impact on IS Education," Journal of Information Systems Education, V20 N2 p137-144, 2009.

[2] D. M. Boyd and N. B. Ellison, "Social network sites: Definition, History, and Scholarship," Journal of Computer-Mediated Communication, 13(1), 210-230, 2007 http://dx.doi.org/10.1111/ j.1083-6101.2007.00393.x

[3] A. McLennan and G. Howell, "Social networks and the challenge for public relations," Asia Pacific Public Relations Journal, 11, $11-19,2010$

[4] Wang, M., Fix, R. and Bock, L. "Blogs: Useful Tool or Vain Indulgence?" In E-learn 2005, World Conference on E-Learning, 24-28, 2004.

[5] A. Davi, M. Frydenberg and G. J. Gulati, "Blogging across the disciplines: Integrating technology to enhance liberal learning," MERLOT Journal of Online Learning and Teaching, 3(3), 222$232,2007$.

[6] R. Klamma, M. Chatti, A., Duval E., Hummel H., Hvannberg E. H., Kravcik M., Law E., Naeve A., Scott P., "Social Software for Life-long Learning," Educational Technology \& Society, 10 (3), 72-83, 2007.
[7] R. Faizi, A. El Afia and R. Chiheb, "Exploring the Potential Benefits of Using Social Media in Education," International Journal of Engineering Pedagogy (iJEP). eISSN: 2192-4880, 2013.

[8] C. Brodahl and N. K. Hansen, "Education students' use of collaborative writing tools in collectively reflective essay papers". Journal of Information Technology Education: Research, 13, 91-120, 2014.

[9] L. A. Annetta, J. Minogue, S. Y. Holmes and M. T. Cheng, "Investigating the impact of video games on high school students' engagement and learning about genetics," Computers \& Education, 53, 74-85, 2009. http://dx.doi.org/10.1016/j.compedu. 2008.12.020

[10] P. D. Chen, A. D. Lambert and K. R. Guidry, "Engaging online learners: The impact of web-based technology on college student engagement," Computer \& Education, 54, 1222-1232, 2010. http://dx.doi.org/10.1016/j.compedu.2009.11.008

[11] R. Junco, "The Relationship Between Frequency of Facebook Use, Participation in Facebook Activities, and Student Engagement," Computers \& Education, 58, 162-171, 2012. http://dx.doi.org/10.1016/j.compedu.2011.08.004

[12] C. Rutherford, "Using Social Media to Support Student Engagement," Retrieved from http://www.drcamillerutherford.com/2012/02/using-social-mediato-support-student.html, 2012.

[13] K. Krause (2007), "New perspectives on engaging first year students in learning. Brisbane: Griffith Institute for Higher Education," Available online: http://www.griffith.edu.au/centre/gihe, 2007.

[14] C. McLoughlin and M. J. W. Lee, "Social software and participatory learning: Extending pedagogical choices with technology affordances in the Web 2.0 era". In R. Atkinson \& C. McBeath (Eds.), ICT: Providing choices for learners and learning. Proceedings of the 24th ASCILITE Conference, 664-675. Singapore, December 2-5, 2007.

[15] R. Faizi, A. El Afia and R. Chiheb, "Social Media: An Optimal Virtual Environment for Learning Foreign Languages," International Journal of Emerging Technologies in Learning (iJET) 9(5): 64-66, 2014. http://dx.doi.org/10.3991/ijet.v9i5.3911

[16] J. Paul, V. Baker and J. Cochran, "Effect of Online Social Networking on Student Academic Performance," Computers in Human Behavior, 28(6), 2117-2127, 2012. http://dx.doi.org/10.1016/ j.chb.2012.06.016

[17] K. Purcell, J. Buchanan and L., Friedrich "The Impact of Digital Tools on Student Writing and How Writing is Taught in Schools," Retrieved from http://www.pewinternet.org/2013/07/16/theimpact-of-digital-tools-on-student-writing-and-how-writing-istaught-in-schools, 2013.

[18] P. Sherer and T. Shea, "Using online video to support student learning and engagement," College Teaching, 59(2), 56-59, 2011. http://dx.doi.org/10.1080/87567555.2010.511313

[19] C.J. Eick and D.T. King, "Non-science majors' perceptions on the use of YouTube video to support learning in an integrated science lecture," Journal of College Science Teaching, 42(1), 26-30, 2012.

\section{AUTHORS}

R. Faizi, R. Chiheb, and A. El Afia are with ENSIAS, Mohammed V University, Rabat, Morocco (e-mail: faizi@ensias.ma, chiheb@ensias.ma, elafia@ensias.ma).

Manuscript received 12 July 2015. Published as resubmitted by the authors 15 November 2015. 